\title{
Elastic Properties Modeling for Identification of Prospective Reservoir Zones in the Carbonate Reservoir, MRD Field in the North East Java Basin
}

\author{
Pemodelan Properti Elastik untuk Identifikasi Zona Reservoir Prospektif pada Reservoir Karbonat, \\ Lapangan "MRD" Cekungan Jawa Timur Utara
}

\author{
Mordekhai* dan Sonny Winardhi \\ Institut Teknologi Bandung, \\ Jl. Ganesa 10 Bandung, Indonesia, 40132 \\ *Email: dekha.68010@gmail.com
}

Submit: 11 Oktober 2017; Revised: 24 Juli 2019; Accepted: 31 Agustus 2019

\begin{abstract}
MRD" field is an oil and gas field which located in Rembang Zone. One of the hydrocarbon zones in this field lies in Ngimbang Formation. Reservoir in this field has a lifespan of Middle Eocene to Early Oligocene. Reservoir of this formation is carbonate rocks and dominated by calcite and dolomite minerals. One of the uniqueness of this kind of reservoir is the pore shape which quite complex. In this study, reservoir characterization which performed on this field is based on elastic properties modelling. Elastic Properties modelling which was conducted in this field can provide an output of the pore shape, aspect ratio, and the fraction of each respective poresforms that exist in this field's reservoir zone. Therefore the primary data such as petrophysical data, XRD (X-Ray Diffraction), and the data of other reservoir parameters are needed for more accurate results obtained with real conditions. The result of this modelling shows that the shape of the pores in the reservoir zone at any depth can be predicted. Distribution of pore shapes that exist in the two wells can be used as a reference for prospective determination of hydrocarbon zones in "MRD" field.

Keywords: carbonate, reservoir, elastic properties, pore shape
\end{abstract}

Abstrak: Lapangan "MRD" merupakan lapangan minyak
dan gas bumi yang terletak pada Zona Rembang. Salah
satu zona hidrokarbon pada lapangan ini terletak pada
Formasi Ngimbang. Reservoir pada formasi ini terdapat
pada batuan karbonat yang didominasi oleh mineral kalsit
dan dolomit. Reservoir karbonat memiliki sifat yang unik
dibanding reservoir lainnya. Salah satu keunikannya yaitu
bentuk porinya yang cukup kompleks. Pada penelitian ini,
karakterisasi reservoir yang dilakukan pada lapangan ini
adalah berupa pemodelan properti elastik. Pemodelan prop-
erti elastik ini dilakukan dengan menentukan nilai modulus
bulk dan modulus shear pada sumur "MRD1" dan "MRD2"
dengan menggunakan bermacam-macam pori inklusi yang
memiliki aspect ratio berbeda-beda. Hasil kalkulasi yang di-
dapat dengan pendekatan metoda DEM (Differential Effec-
tive Medium) kemudian akan dicocokkan dengan data obser- vasi. Sehingga pemodelan ini dapat memberikan gambaran mengenai bentuk pori, aspect ratio, dan fraksi dari setiap masing-masing bentuk pori yang ada pada zona reservoir lapangan ini. Oleh karena itu data-data primer seperti data petrofisika, XRD (X-Ray Diffraction), serta data parameter reservoir lainnya diperlukan agar hasil yang didapat semakin akurat dengan kondisi sebenarnya. Hasil dari pemodelan ini menunjukkan bahwa bentuk pori pada zona reservoir di setiap kedalamannya dapat diprediksi. Sumur "MRD1" memiliki lebih banyak stiff pore dibanding sumur "MRD2". Identifikasi persebaran bentuk pori yang ada pada kedua sumur ini dapat dijadikan acuan untuk menentukan reservoir yang prospektif.

Kata kunci: karbonat, reservoir, properti elastik, bentuk pori

\section{PENDAHULUAN}

Salah satu reservoir hidrokarbon yang banyak terdapat di dunia adalah reservoir karbonat. Karakterisasi reservoir pada kasus ini seringkali mengalami kendala yang disebabkan keadaan yang "unique" pada batuan karbonat. Salah satu penyebab keunikan dalam reservoir ini adalah tipe bentuk porinya yang berbeda-beda (Asquith dan Krygowski, 2004).

Pada kasus reservoir lain, umumnya jika respon Vp menunjukkan nilai yang tinggi maka diasosiasikan dengan porositas yang rendah. Namun pada kasus batuan karbonat hal ini belum tentu tepat, karena bisa saja nilai Vp yang tinggi berada pada porositas tinggi yang memiliki bentuk pori stiff.

Hal ini membuat penulis memberikan perhatian khusus dalam mempelajari respon kecepatan gelombang $\mathrm{P}$ dan gelombang S (Vp dan Vs) pada batuan karbonat. Penulis memilih untuk melakukan pemodelan properti elastik dalam kasus ini karena salah satu fungsi dari analisis ini adalah untuk melihat respon kecepatan pada reservoir karbonat 


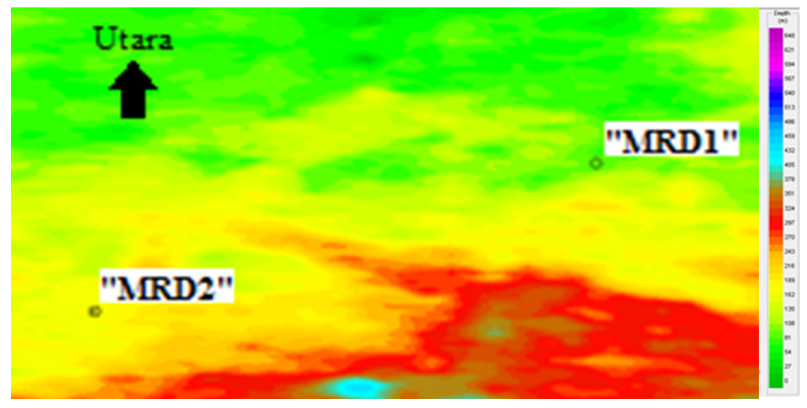

Gambar 1. Peta isopach daerah target pada sumur "MRD1" dan "MRD2"

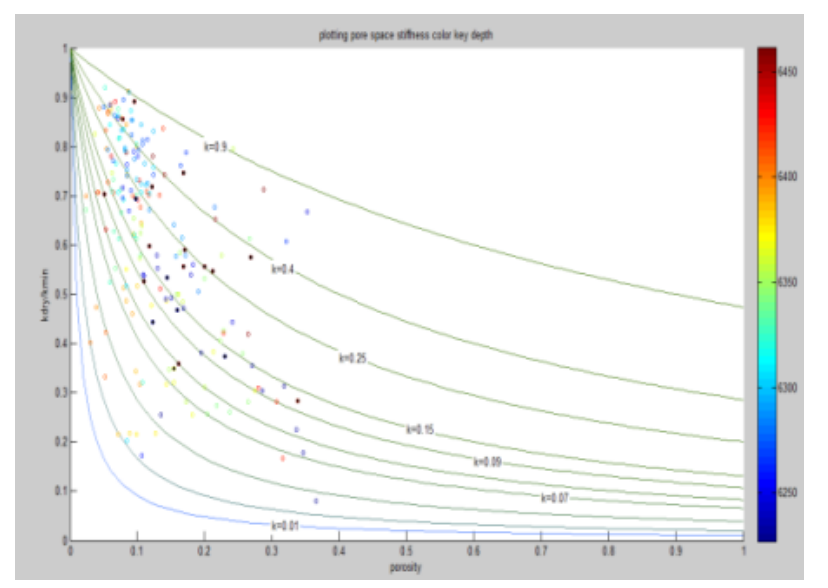

Gambar 2. Plot kurva pore space stiffness "MRD1".

yang disebabkan perbedaan bentuk pori pada batuan ini, sehingga bentuk pori tersebut dapat diidentifikasi dengan baik.

Daerah target pada penelitian kali ini terdapat di sumur "MRD1" dan "MRD2" (Gambar 1). Formasi dari daerah yang tergolong reservoir karbonat ini adalah Formasi Ngimbang yang termasuk ke dalam anggota Zona Rembang. Secara umum mineral yang mendominasi pada batuan ini adalah kalsit dan dolomit dengan sisipan shale.

\section{METODOLOGI}

Sebagai langkah awal, untuk menentukan modulus elastis mineral, data fraksi tiap mineral diperoleh dari data XRD. Dari data XRD ini kemudian akan diinterpolasi ke tiap kedalaman berdasarkan acuan Volume of Shale. Lalu dengan menentukan modulus bulk dan shear tiap mineral, kita dapat menentukan modulus elastis pada solid rock di tiap kedalaman.

Lalu dengan menggunakan persamaan Batzle Wang dan Biot Gassmann, nilai modulus bulk fluida dan dry rock dapat ditentukan. Dengan parameter-parameter inilah perkiraan $\mathrm{AR}$ (aspect ratio) dapat ditentukan dari plotting pore space stiffness seperti Gambar 2 dan 3.

Dari hasil plotting ini, didapat 3 percobaan yang menggunakan aspect ratio berbeda-beda yang nantinya akan dilihat percobaan mana yang menghasilkan error terkecil.

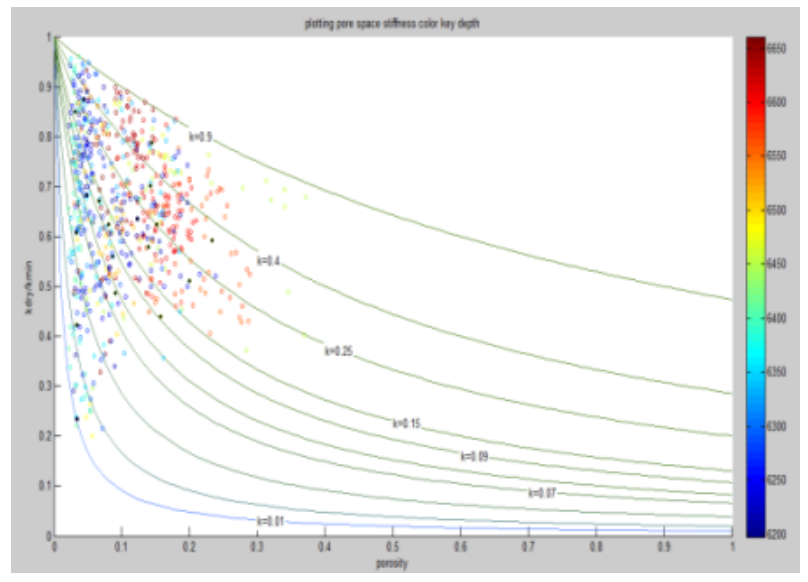

Gambar 3. Plotting kurva pore space stiffness "MRD2".

Tabel 1. Tabel percobaan dengan aspect ratio yang beragam.

\begin{tabular}{|c|c|c|c|}
\hline & Percobaan 1 & Percobaan 2 & Percobaan 3 \\
\hline Stiff Pore & 0.25 & 0.4 & 0.9 \\
\hline Reference Pore & 0.15 & 0.15 & 0.15 \\
\hline Soft Pore & 0.09 & 0.07 & 0.01 \\
\hline
\end{tabular}

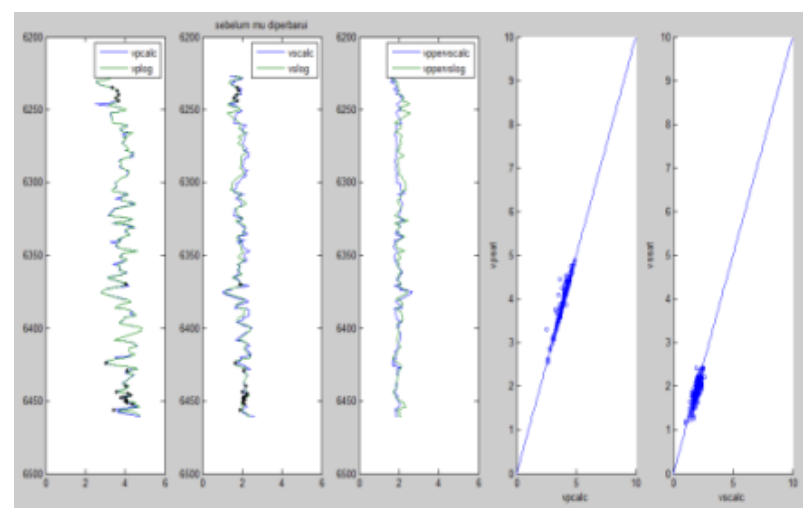

Gambar 4. Percobaan fitting Vp, Vs, dan Vp/Vs dengan menggunakan DEM pada "MRD1".

Aspect ratio yang digunakan dalam pemodelan ini dapat dikelompokan menjadi 3, yaitu aspect ratio stiff pore, reference pore, dan soft pore.

Percobaan diatas terlebih dahulu dilakukan pada data XRD untuk menguji kevalidan data (Tabel 1). Dari aspect ratio yang ada serta pemodelan fraksi tiap bentuk pori yang telah ditentukan, nilai $\mathrm{Vp}, \mathrm{Vs}, \mathrm{Vp} / \mathrm{Vs}$ kalkulasi dapat ditentukan dengan menggunakan metoda DEM (Differential Effective Medium). Setelah mendapat hasil Vp dan Vs yang paling cocok pada data XRD, percobaan yang terbaik kemudian diaplikasikan pada seluruh kedalaman. Aspect ratio yang memiliki error terkecil pada percobaan di kedua sumur ini yaitu pada percobaan 3 .

Gambar 4, 5 dan 6 merupakan percobaan dengan hasil yang terbaik (percobaan 3) yang dilakukan dengan menganalisis fitting data Vp Vs kalkulasi dengan Vp Vs observasi dan juga crossplot antara Vp Vs kalkulasi dan Vp Vs observasi. 


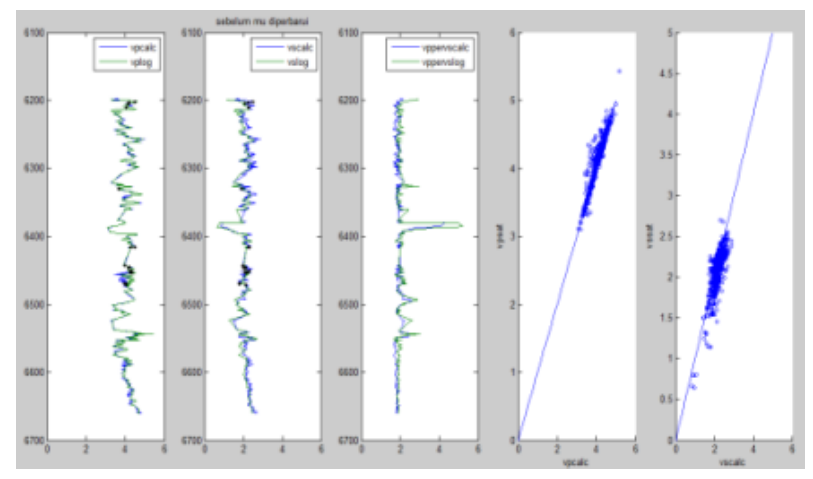

Gambar 5. Percobaan fitting Vp, Vs, dan Vp/Vs dengan menggunakan DEM pada "MRD2".

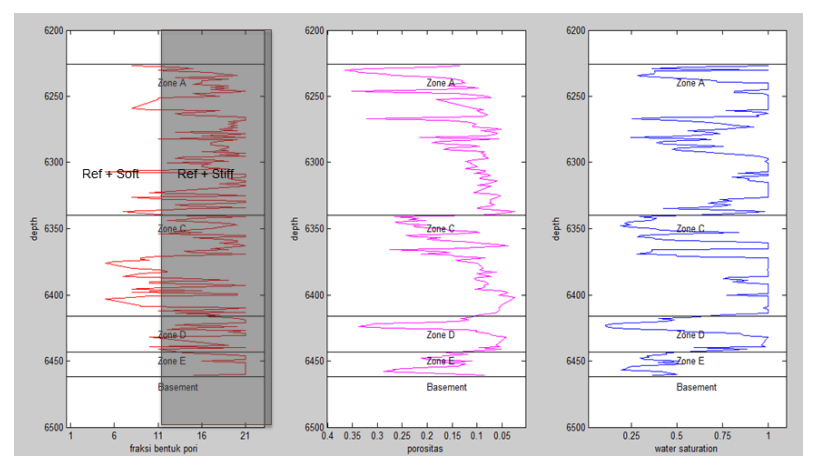

Gambar 6. Dari kiri ke kanan: log fraksi tiap bentuk pori, porositas, water saturation pada "MRD1".

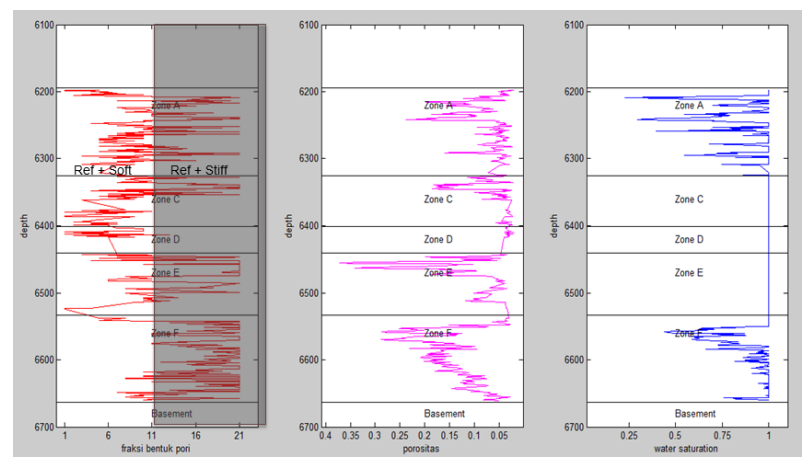

Gambar 7. Dari kiri ke kanan: log fraksi tiap bentuk pori, porositas, water saturation pada "MRD2".

\section{HASIL DAN PEMBAHASAN}

Untuk menentukan zona reservoir yang prospektif, analisis dilakukan berdasarkan pertimbangan nilai dari porositas, saturasi air, dan fraksi bentuk pori pada sumur "MRD1" dan "MRD2".

Dengan menggunakan metode quick look dari Gambar 8, 9, 10, 11 dapat dilihat bahwa zona yang berada di depth yang dalam, semakin didominasi oleh stiff pore. Sumur "MRD1" lebih banyak mengandung stiff pore dibanding "MRD2". Selanjutnya akan dilakukan analisis crossplot pada kedua sumur untuk mengetahui sensitivitas Vp dan Vs terhadap perbedaan bentuk pori.

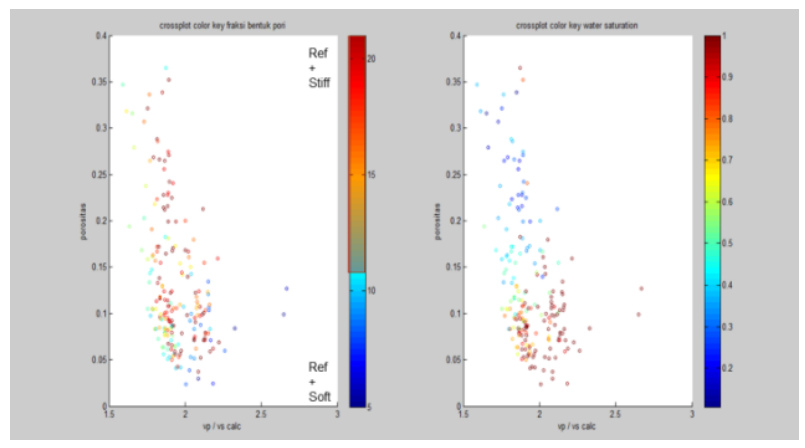

Gambar 8. Crossplot Vp/Vs dengan porositas dengan color key fraksi bentuk pori (kiri) dan saturasi air (kanan) pada sumur "MRD1".

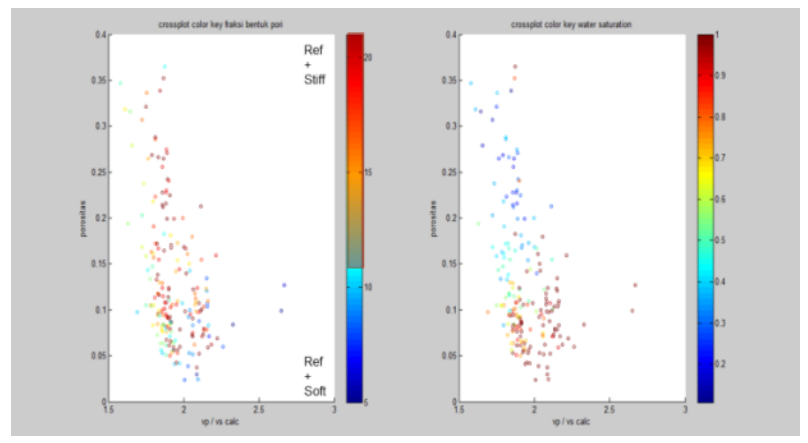

Gambar 9. Crossplot Vp/Vs dengan porositas dengan color key fraksi bentuk pori (kiri) dan saturasi air (kanan) pada sumur "MRD1" setelah dilakukan subtitusi gas.

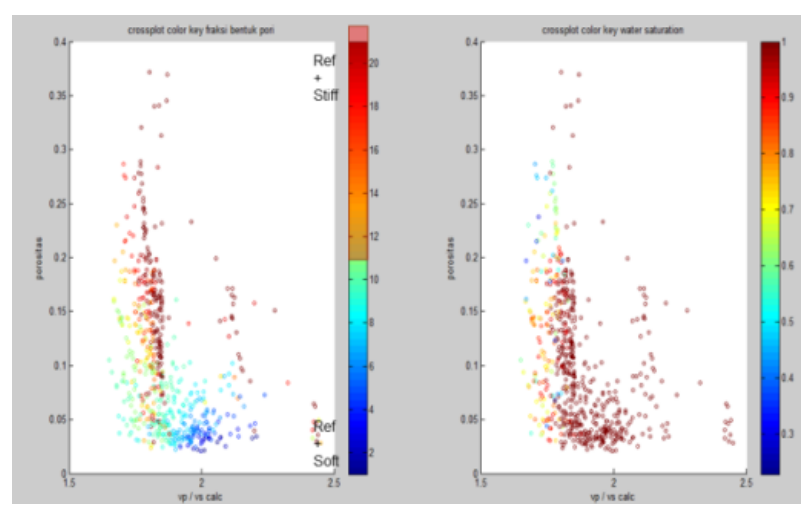

Gambar 10. Crossplot Vp/Vs dengan porositas dengan color key fraksi bentuk pori (kiri) dan saturasi air (kanan) pada sumur "MRD2".

Pada sumur "MRD1", tidak terlihat pemisahan yang baik antara stiff pore dan soft pore karena sumur "MRD1" didominasi oleh stiff pore. Setelah dilakukan subtitusi gas, crossplot $\mathrm{Vp} / \mathrm{Vs}$ dengan porositas tidak terjadi perubahan yang signifikan. Bentuk pori yang stiff tidak sensitif terhadap pergantian fluida. Hal ini dikarenakan bentuk pori yang stiff memiliki kecepatan yang besar (lebih sulit ditekan dibanding soft pore) sehingga jika dilakukan subtitusi gas (yang memiliki kecepatan lebih rendah daripada minyak) tidak terjadi penurunan kecepatan yang signifikan. 


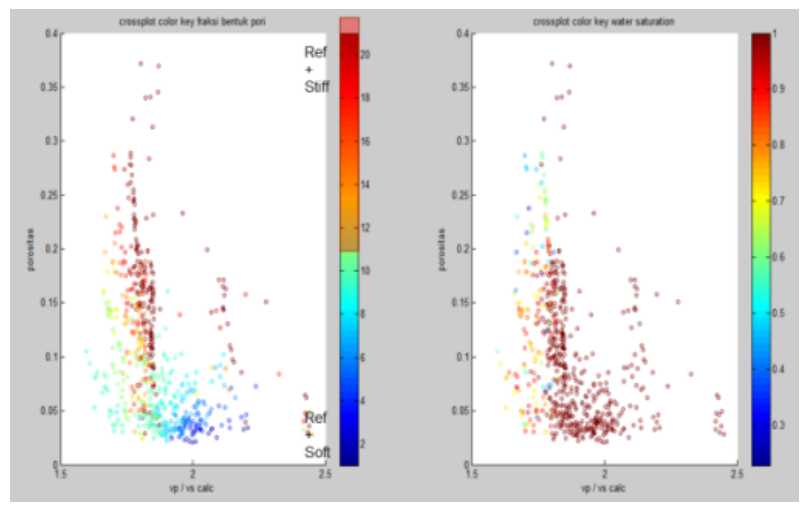

Gambar 11. Crossplot Vp/Vs dengan porositas dengan color key fraksi bentuk pori (kiri) dan saturasi air (kanan) pada sumur "MRD2" setelah dilakukan subtitusi gas.

Sementara pada sumur "MRD2" kemunculan soft pore pada daerah yang tersaturasi hidrokarbon dapat diidentifikasi. Namun pada daerah yang tersaturasi air, sensitivitas kecepatan terhadap perbedaan bentuk pori tidak dapat dibedakan. Hal ini disebabkan saturasi air yang tinggi menyebabkan nilai kecepatan tinggi, sehingga kemunculan soft pore tidak sensitif terhadap nilai kecepatan.

Setelah dilakukan subtitusi gas, crossplot $\mathrm{Vp} / \mathrm{Vs}$ dengan porositas terjadi perubahan nilai. Nilai Vp dan Vs kalkulasi yang ada menunjukkan penurunan nilai. Hal ini dikarenakan pada sumur "MRD2" bentuk pori yang ada lebih beragam dibanding sumur "MRD1". Bentuk pori yang soft memiliki kecepatan yang lebih kecil dibanding stiff pore sehingga jika dilakukan subtitusi gas (yang memiliki kecepatan lebih rendah daripada minyak) terjadi penurunan kecepatan dari kecepatan sebelumnya.

\section{KESIMPULAN}

Pemodelan properti elastik yang digunakan pada sumur "MRD1" dan "MRD2" dapat digunakan untuk mengidentifikasi persebaran bentuk pori inklusi secara vertikal dengan mencocokkan Vp Vs kalkulasi dengan observasi.Pada percobaan pemodelan dengan menggunakan aspect ratio yang berbeda-beda dapat dilihat bahwa semakin besar rentang aspect ratio yang digunakan pada pemodelan, maka semakin kecil error yang ada, karena semakin besar cakupan terhadap data observasi.

Secara umum bentuk pori pada Lapangan "MRD" didominasi oleh stiff pore dibanding soft pore. Pada daerah dengan saturasi air tinggi, perbedaan bentuk pori stiff dan soft tidak dapat dibedakan. Hal ini merupakan salah satu yang menyebabkan ambiguitas pada interpretasi data. Simulasi subtitusi gas pada zona reservoir menyebabkan sensitivitas $\mathrm{Vp} / \mathrm{Vs}$ semakin baik pada bentuk pori soft pore namun tidak pada stiff pore.

Dari studi ini didapatkan bahwa sumur "MRD1" mempunyai persentase stiff pore (vuggy) lebih banyak dibanding sumur "MRD2". Hal ini juga didukung oleh ditemukannya mineral dolomit (dolomitisasi akibat meteorite water) pada sumur "MRD1". Sehingga dapat disimpulkan bahwa lingkungan pengendapan sumur "MRD1" lebih ke arah daratan (landward) dibanding sumur "MRD2", sesuai dengan peta isopach yang menunjukkan bahwa ketebalan Formasi Ngimbang karbonat pada sumur "MRD1" lebih tipis dibanding sumur "MRD2".

\section{DAFTAR PUSTAKA}

Asquith, G. dan D. Krygowski., 2004. Basic Well Log Analysis. Tulsa: American Association of Petroleum Geologists.

Bishop, M. G., 2000. Petroleum systems of the Northwest Java Province, Java and offshore southeast Sumatra, Indonesia: U. S. Geological Survey Open File Report 99$50 R$.

Grandis, H., 2009. Pengantar Pemodelan Inversi Geofisika: Himpunan Ahli Geofisika Indonesia.

Hampson, D. dan Russell, H., 2008. Theory of the Strata Program, Hampson-Russel Software Services Ltd.

Li, Q., 2015. Sparse-Spike Impedance Inversion. HampsonRussel Software Service Ltd. 